\title{
Rock Mechanics Practices and Experiences at Xstrata Mount Isa Copper Operations
}

\author{
H.C.J. Esterhuizen Xstrata Copper, Australia
}

N. Slade Xstrata Copper, Australia

J.L. Sloane Xstrata Copper, Australia

\begin{abstract}
The underground mining environment at Mount Isa Copper Operations (MICO) has over the years presented interesting and challenging rock mechanics related issues. Within the same orebody there can be vast differences in how the rock mass behaves. Factors such as rock type, composition, geological structures, support quality and induced stress changes from past and current mining can have a significant influence on how the overall rock mass will behave. Recently there have been several examples highlighting the influence of these on the rock mass. In order to control rock mass behaviour, good quality support is important. Over the years there have been numerous examples of support testing and support improvements at Mount Isa Mines. More recently additional work was done on cable bolts and corrosion of ground support.
\end{abstract}

\section{Introduction}

MICO is a large and integrated mining complex located in Mount Isa, Queensland, Australia (Figure 1). The underground mining operation is comprised of two copper mines, X41 and Enterprise, mining at a rate in excess of six million tonnes of copper ore per annum.

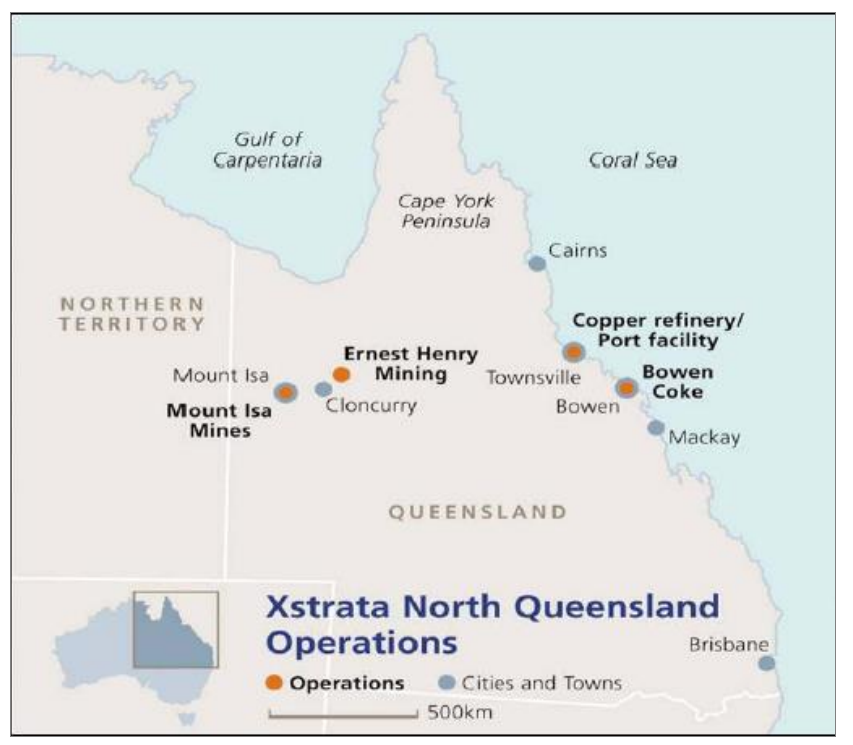

\section{Figure 1 Location of MICO}

A number of copper orebodies are being extracted including the 1100 orebody, the 3000 , the 3500 and N3500 orebodies. The copper orebodies are accessed via two vertical shafts (R62 and X41) as well as a decline from surface. The northern deep copper (Enterprise mine) is serviced by R62 Shaft which hauls both ore and people. The U62 shaft and the internal M62 shaft are used for hoisting of ore.

MICO uses the sublevel open stoping mining method throughout its operations. This paper will describe some of the recent rock mechanics experiences and testing from the mine. 


\section{Rock mass background -3500 OB}

The copper orebodies at Mount Isa are hosted in the sedimentary rocks of Urquhart Shales within the Mount Isa Group. The majority of the copper orebodies are terminated down dip by a major sheared and faulted, carbonaceous mylonite zone. This feature is locally known as the Basement Contact Fault (Figure 2).

The 3500 orebody is tabular, being taller and thinner in aspect when compared to the other orebodies at Enterprise. Ore is often bound by bedded barren shales and has average grades that are $20 \%$ higher than the other orebodies.

The success of mining ore in this area is affected by the poor ground conditions in the vicinity of the Basement Contact Zone (BCZ) fault. It presents mining challenges in almost all intersections of the BCZ with development mining and stoping.

Ground conditions in the MICO are commonly dominated by the presence of a few major geological structures as well as domains of bedded rock. Most of the extraction areas in the MICO are affected by the influence of on-going mining induced changes in stress.

Faulting within the $3500 \mathrm{OB}$ (the focus of the case studies in this document) results in relatively poor rock mass conditions. The rock mass adjacent to large faults in this orebody is characterised by large areas affected by strong bedding parallel shear planes. The shear planes are typically filled with quartz, dolomite, graphitic rubble and chalcopyrite and varies in thickness from $<10 \mathrm{~cm}$ to $6 \mathrm{~m}$. The faults vary in thickness from 1-5 $\mathrm{m}$ and regularly cause stope overbreak. Overbreak from faults can be wedge types of failure and/or unravelling of weak rock within, or adjacent to, the faults. Faults can also contribute to issues during the development of drives. An example of a number of faults in the 3500 orebody is shown in Figure 2. More recent experiences in the northern area (North of $6500 \mathrm{mN}$ ) have indicated increased talc associated with some of the faults (through infill and replacement (Foster et al., 2007)), which has resulted in some higher levels of change in the rock mass response to mining activity.

Geological structure, (other than major faulting) includes variably folded continuous bedding and a number of joint sets. Siliceous and dolomitic alteration halos are present in the mineralised areas.

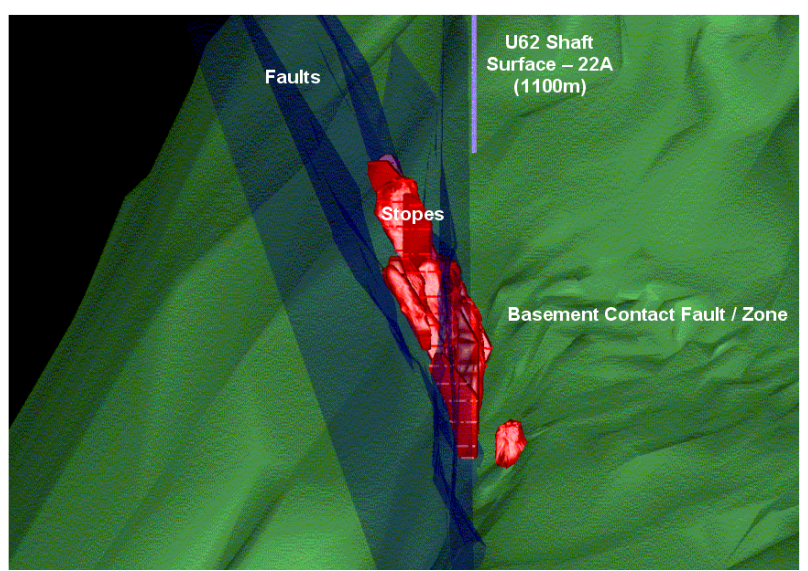

\section{Figure 2 Section view illustration of stopes and major geological structure in Enterprise mine}

Bedding dips at approximately $65^{\circ}$ to the west. Joints may be encountered steeply dipping to the east, shallow dipping to the east and at varying angles of dip in both northerly and southerly dip-directions, in copper barren areas. The alteration halo, locally termed 'silica-dolomite' encloses the mineralisation and produces rocks that are more brittle than the adjacent unaltered bedded shales.

Uniaxial compressive strengths (UCS) of the main rock types encountered during mining activity range from 85-230 MPa, with an elastic modulus in the 50-90 GPa range (Tarrant and Lee, 1984). Fractured Siliceous Shales (containing copper ore) are in the upper quartile of the UCS range. More recent areas tested from the far northern areas of Enterprise mine (northern 3500 orebody) have returned values as low as $30 \mathrm{MPa}$. 


\section{Rock mass behaviour -3500 OB}

The 3500 orebody has a strike length of approximately $1100 \mathrm{~m}$ with a $\mathrm{N}-\mathrm{S}$ strike orientation. It has a vertical height of approximately $200 \mathrm{~m}$ with a dip length of approximately $500 \mathrm{~m}$ (dips at approximately $65^{\circ}$ ). The rock mass response to mining in the southern areas of the orebody has been relatively consistent and predictable. The higher talc content and extensive faulting of the northern areas (North of $6500 \mathrm{mN}$ ) of the orebody was expected to lead to a more pronounced rock mass response.

\subsection{Rock mass behaviour is driven by several factors}

- Rock mass strength.

- Rock mass composition.

- Presence and properties of geological features.

- Stress and stress changes.

- Deformation.

- Mining methods, stope size and shape, and layouts.

- Ground support.

\subsection{Distinct domains}

Two of the more distinct behavioural differences are the amount of deformation and failure experienced between two distinct domains within this orebody:

- North S3500 domain:

North of $6500 \mathrm{~N}$ - called North domain for rest of this paper.

- South S3500 domain:

South of $6500 \mathrm{~N}$ - called South domain for rest of this paper.

There is a more gradual change between the two domains than this distinct domaining suggests, but for discussion purposes the $6500 \mathrm{mN}$ line will be considered as the boundary. A description of the domains follows:

\subsubsection{North domain}

- Increased talc content in some areas. The talc can occur as both infill and replacement. Talc can occur in relatively high concentrations $(>30 \%)$, with the average lower at approximately $8 \%$ for some areas.

- Rock mass has areas that are more densely fractured and bedded.

- Increased creep and deformation on faults and increased deformation during initial drive development.

- More intersection of $\mathrm{N}-\mathrm{S}$ and NNW faults.

- Rocknoise during drive development phase and during stoping.

- Relatively early and small stope firings can trigger increased drive deformation and in stope fall-off.

- Accelerated deformation in access drives during adjacent stope blasting.

- Higher rates of drive closure. This occurs during the development phase and accelerates during stoping.

- An increased likelihood for in-stope fall-off.

- Increased small-scale seismic events (including rocknoise) as faults move and the rock mass deforms. 
- Failure and yielding of tendons and steel fibre reinforced shotcrete due to large deformations.

\subsubsection{South domain}

- Low or no talc content.

- Less densely fractured/bedded.

- Less deformation and creep on faults.

- Fewer fault intersections.

- Minor drive deformation (small scale fracturing and loosening of slabs). There are however, some areas that are influenced by high deformation along the 3500 FW fault.

- Less rocknoise (except during movement associated with faulting).

- Less stope overbreak and dilution.

- Very little seismic activity.

- Minimal yielding of support tendons and steel fibre shotcrete (except during deformation associated with faulting).

Traditionally most of the extraction so far has been focused in the Southern domain. The change in conditions found in the Northern domain and the challenge of identifying changing conditions within the orebody becomes very important. The decisions (ground support decisions or mine scheduling/design/firing decisions) made with changing conditions can have a significant impact on managing risk from a safety and an economic perspective. The two case studies described illustrate the differences experienced at MICO while mining in these domains situated in the same orebody.

\subsection{Case studies of two stopes in different domains}

\subsubsection{South 3500}

General description: More competent ground compared to Northern domain, less mining induced damage and less rock mass deformation and fault movement.

U627 stope: This was a secondary stope situated in the central-west region of S3500 orebody and will be used as an example of the rock mass behaviour in the S3500 domain.

The stope was designed to extract $346,631 \mathrm{t}$ at $4.84 \%$ copper. It had the following dimensions: strike length $=25 \mathrm{~m}$; width $=40 \mathrm{~m}$; height $=140 \mathrm{~m}$. The stope height was reduced to eliminate the possibility of crown overbreak associated with faulting and other mine openings. The main rock type in the stope was Siliceous Shale (C). Fractured Siliceous Shale (FSS) was present in the bottom half of the stope.

Figure 4 show the faults that intersected the planned stope. 35 NS4, NS5 and NS6 were some of the weaker faults that intersected the crown of the stope. These three faults are known to be graphitic (have graphitic infill), and have sheared and fractured zones associated with them. Some of the fault intersections created potential wedges above the crown. 


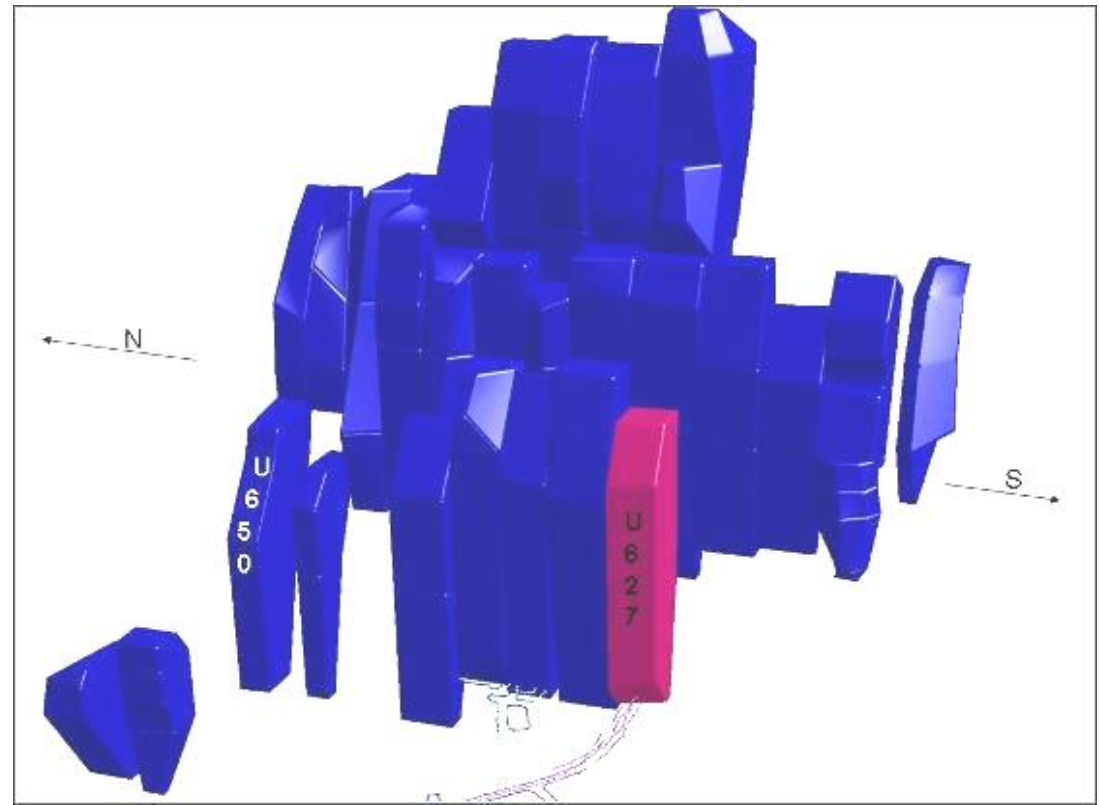

Figure 3 U627 location

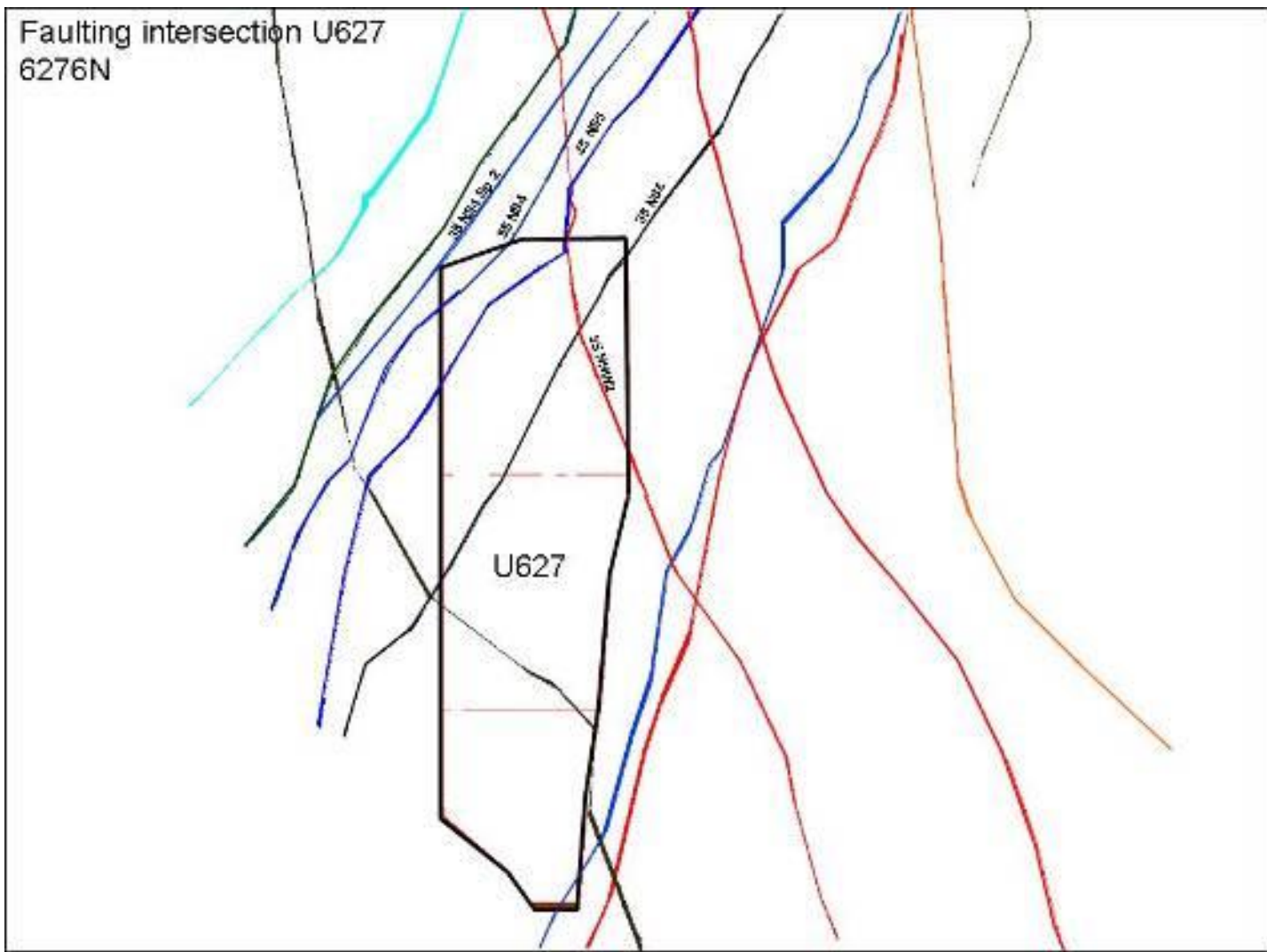

Figure 4 U627 fault intersections

Extraction of U627 was undertaken according to plan and schedule and was a success. No major overbreak or other issues occurred. This performance is typical for the stopes extracted in the southern domain. Figure 5 illustrates the planned mining shape with the actual measured superimposed over the planned. 


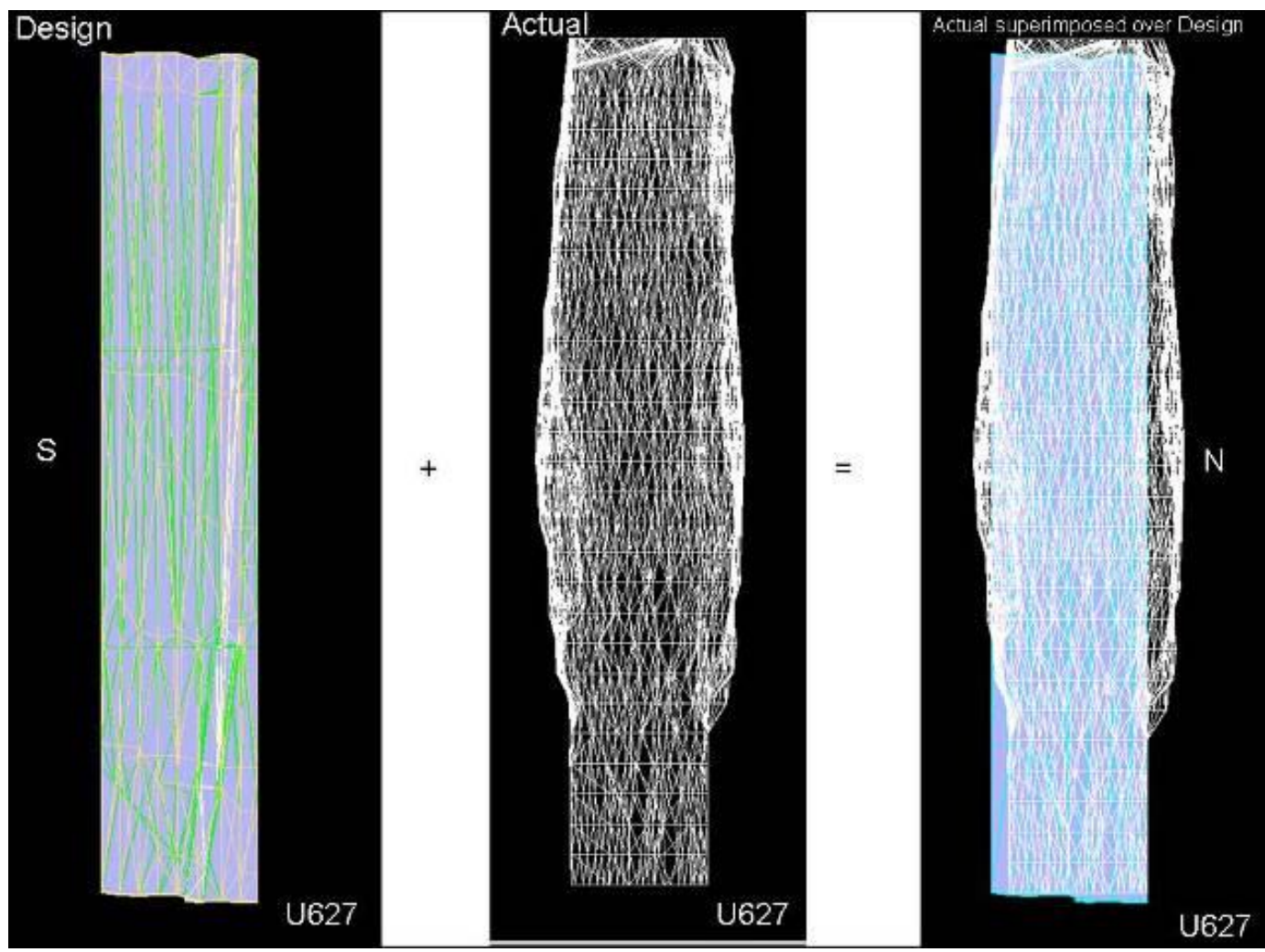

Figure 5 U627 overbreak

\subsubsection{North 3500}

General description: less competent ground, more mining induced damage, more fall-off from within the stopes.

U654 was the first stope to be mined in the North S3500 OB towards the upper levels and the following observations and measurements confirmed the presence of a separate domain as described previously.

In contrast with the previous discussion, the Northern domain has behaved significantly different. During almost all mining cycle activities associated with the U654 stope, differences were observed in the rock mass response to mining activity.

As a result of observations made during pre-stoping activity and in recognition of the differing conditions, a number of design changes were made to the stope design for U654. These included:

- The stope strike span for U654 stope was reduced from $30 \mathrm{~m}$ (as in the Southern domain) to $15 \mathrm{~m}$.

- Apart from the primary resin bar and mesh support, additional support in the form of cable bolts and in some instances steel fibre shotcrete was installed to control drive deformation and reduce the risk associated with deteriorating drive conditions.

- A $20 \mathrm{~m}$ pillar of rock was left in place between U654 and a neighbouring stope due to the potential of mullock and fill dilution affecting the U654 stope production.

- A monitoring program was designed and instigated to monitor both peripheral (drive) and stope deformation and behaviour. 


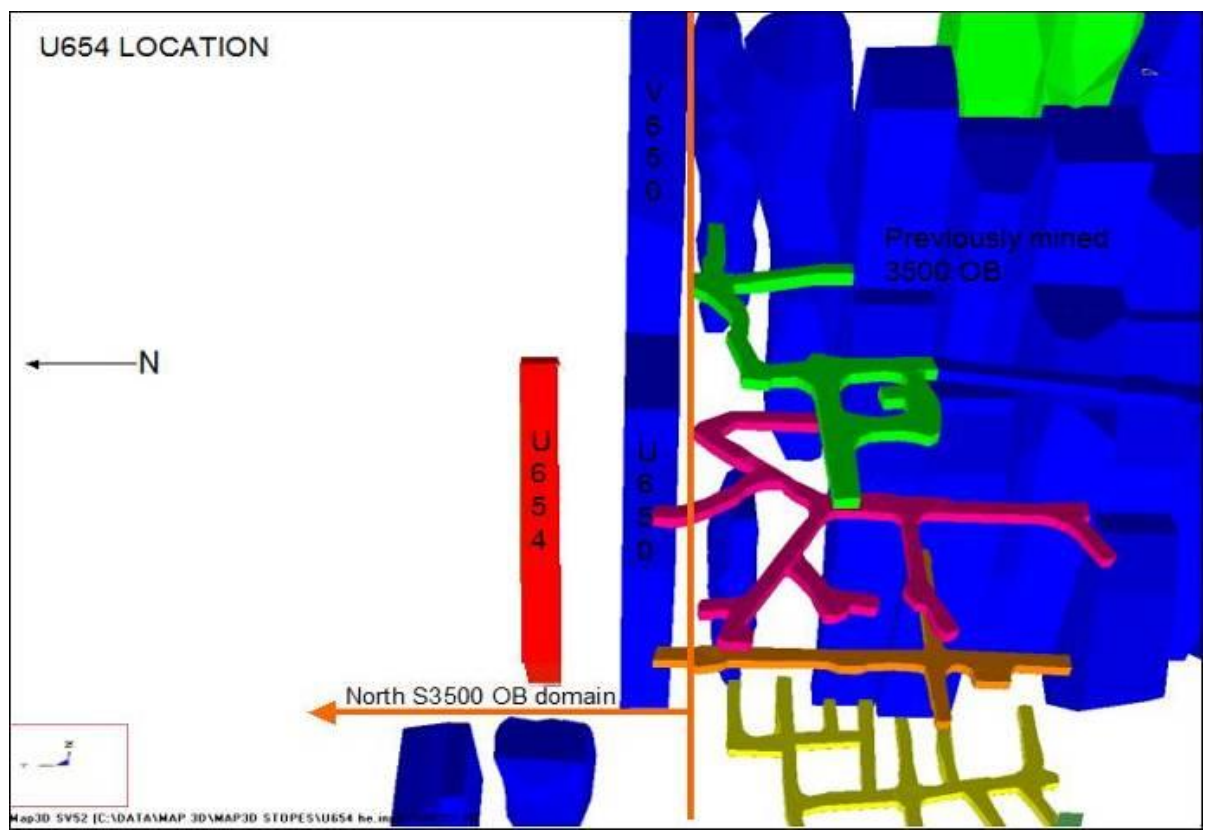

\section{Figure 6 U654 Location}

Increased drive deformation and high loading of support units were common during all phases of the U654 extraction. This increased deformation was attributed to the higher talc content, increased fracturing, fault presence, and increased in situ stress conditions (horizontal). Figure 7 illustrates the high talc content, faulting, shearing and buckling of bedded layers.

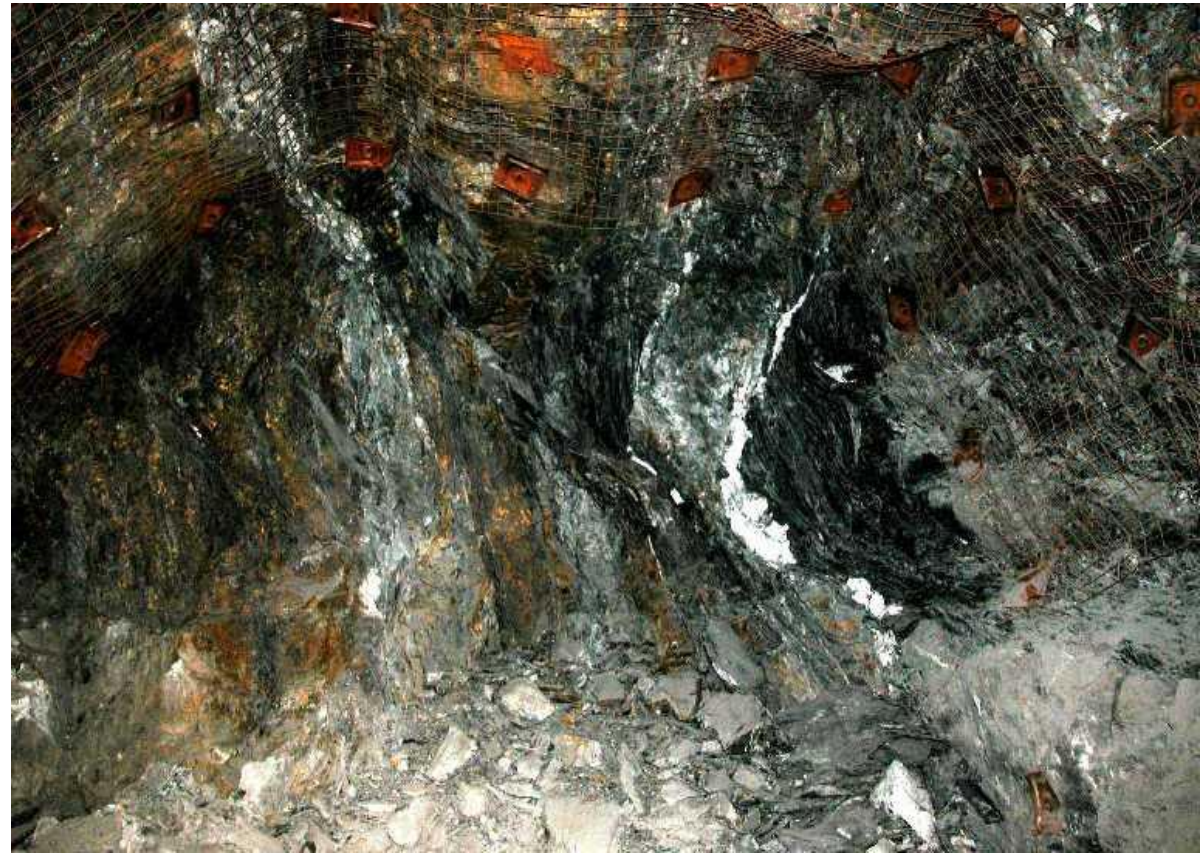

Figure 7 U654 DDR on 27C sub-level (2004)

During the initial U654 cut-off firings, rocknoise and deformation in the access drives increased notably. Although the void was still relatively small, and the firings were relatively small $(\sim 10,000 t)$, the rock mass response was more significant than was expected. Figure 8 outlines some of the history of this stope. 


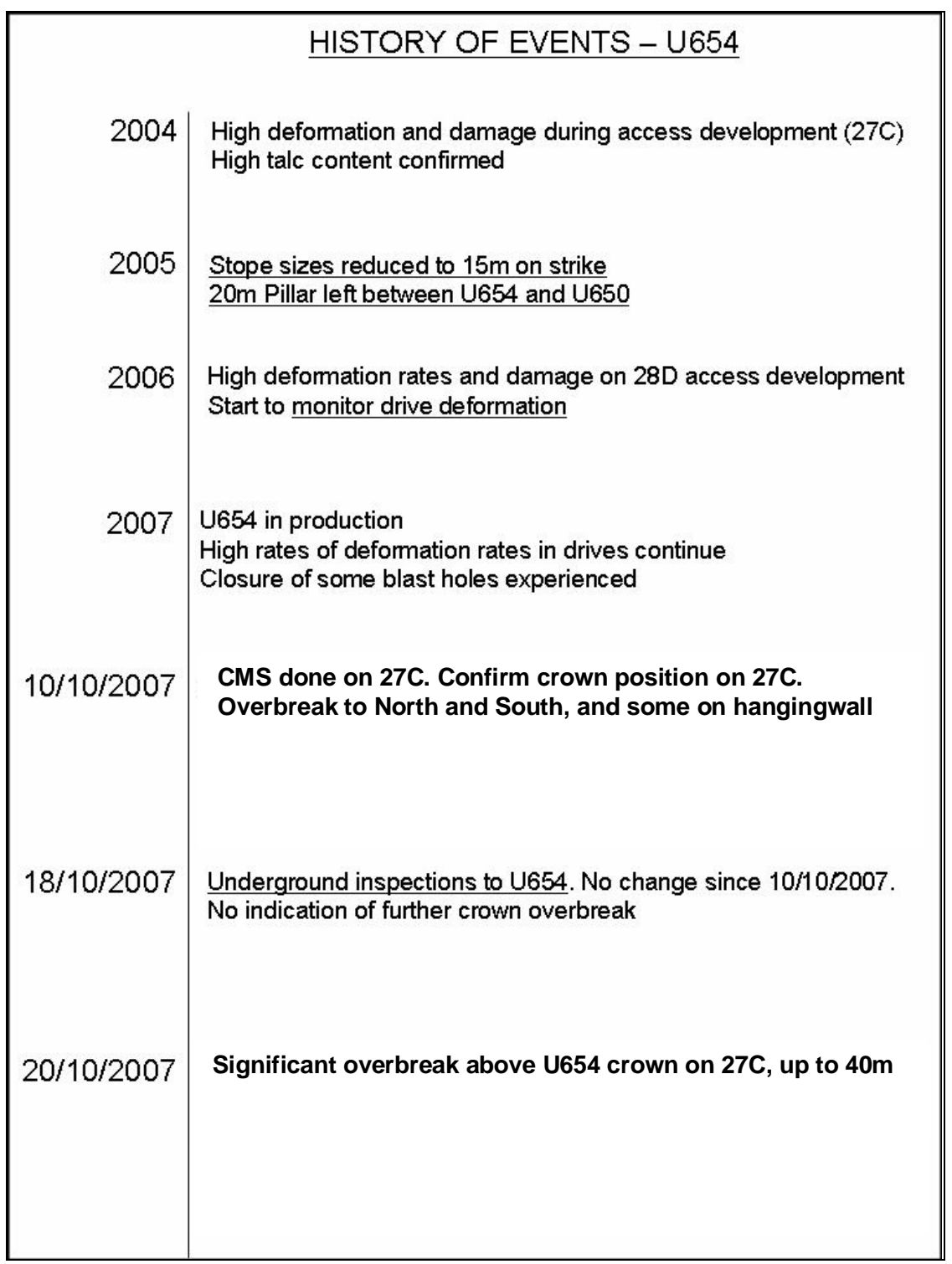

\section{Figure 8 History of events leading up to eventual stope crown overbreak at U654}

It was planned to blast the stope cut-off in three sublevel lifts, and then to blast main ring (MR) one at the bottom lift. It was then planned to fire the remaining rings as one mass firing (102,500 t). During stope extraction the blasting plan was changed on a number of occasions in response to changing rock mass behaviour in and around the stope. A number of blast holes experienced partial closure, access drives deformed noticeably in the sidewall and floor and significant in stope fall-off occurred from the main rings of drilled ore. Access to the stope was restricted due to the deterioration of some development drives, this led to some of the rings not being fired. However the majority of the stope ore was extracted.

Figure 9 illustrates the cracks that formed up to $30 \mathrm{~m}$ away from the stope. Figures 10 and 11 illustrate the drive deformation that occurred. During the development phase prior to stoping it was observed that the drives were deforming at higher than normal rates. Up to $1.5 \mathrm{~m}$ of drive sidewall deformation was measured. Support installed included $20 \mathrm{~mm}$ resin bolts and weld mesh, $6 \mathrm{~m}$ cable bolts into the sidewalls and $100 \mathrm{~mm}$ steel fibre reinforced shotcrete.

The drive deformation on the mid-levels near U654 stope (28D and 29E) exceeded the capacity of some elements of the ground support. Although access was still safely managed through these drives, they were severely damaged. Figure 10 illustrates the damage on 28D level, and Figure 11 illustrates the conditions on 29E. The support on 28D Level did however stand up long enough in order to complete the stope firings. 


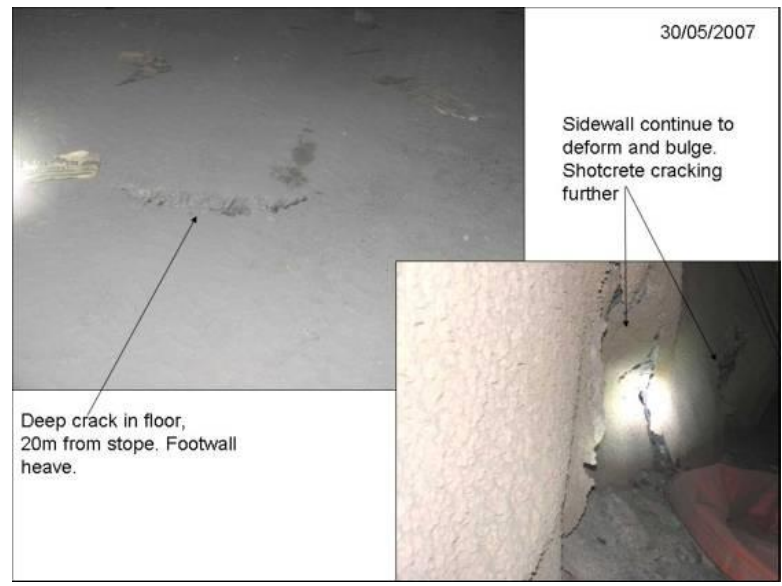

Figure 9 Drive floor and sidewall cracks

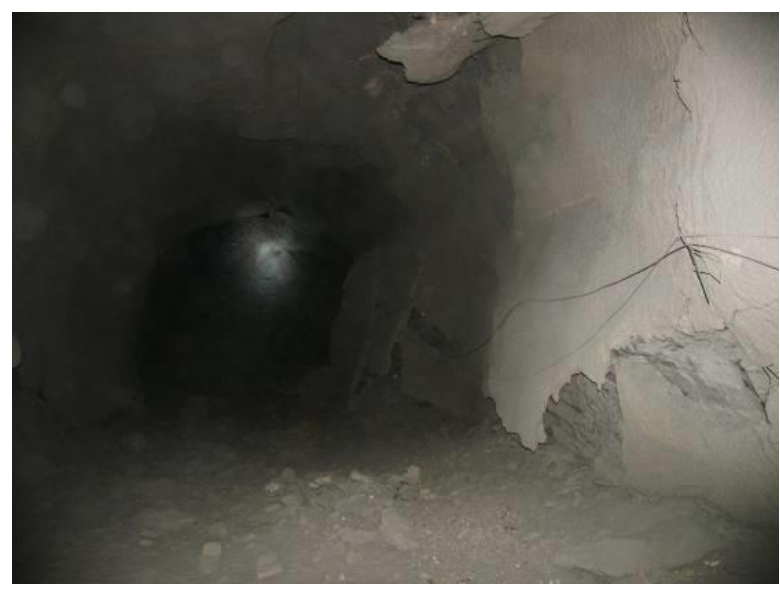

Figure 10 28D Level access drive

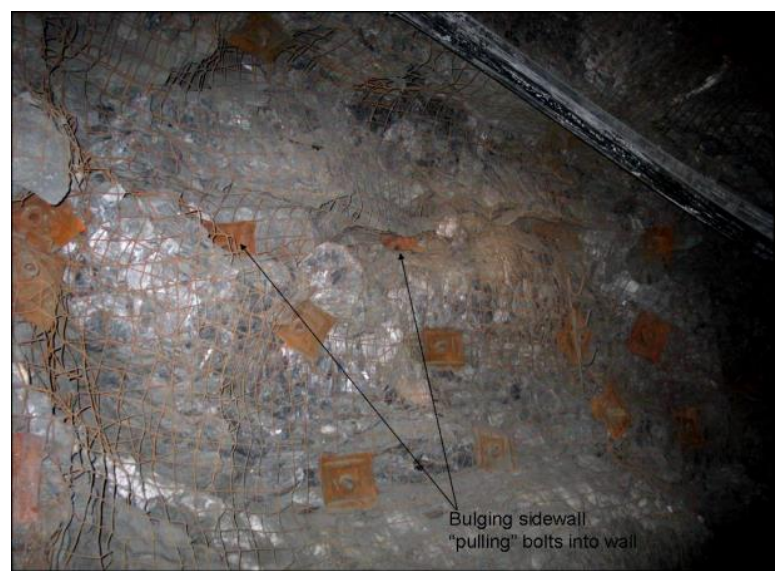

Figure 11 29E Level drive deformation. Note cable bolt plates 'pulled in' as the rock mass deforms around the solid anchored steel

Figure 12 shows the progressive deformation of the sidewalls on $28 \mathrm{D}$ level. This drive was $\mathrm{N}-\mathrm{S}$ orientated with several faults striking parallel to the drive. The major in situ principle stress was interpreted to be $\mathrm{N}-\mathrm{S}$ orientated (horizontal).

There was a two month period in which U654 was mucked but not blasted. Other stopes within $100 \mathrm{~m}$ from U654 continued to be blasted. During this time the rocknoise and the deformation (Figure 12) continued. 
Observations in areas around U654 stope continued to show deformation, cracks developing and audible rocknoise.

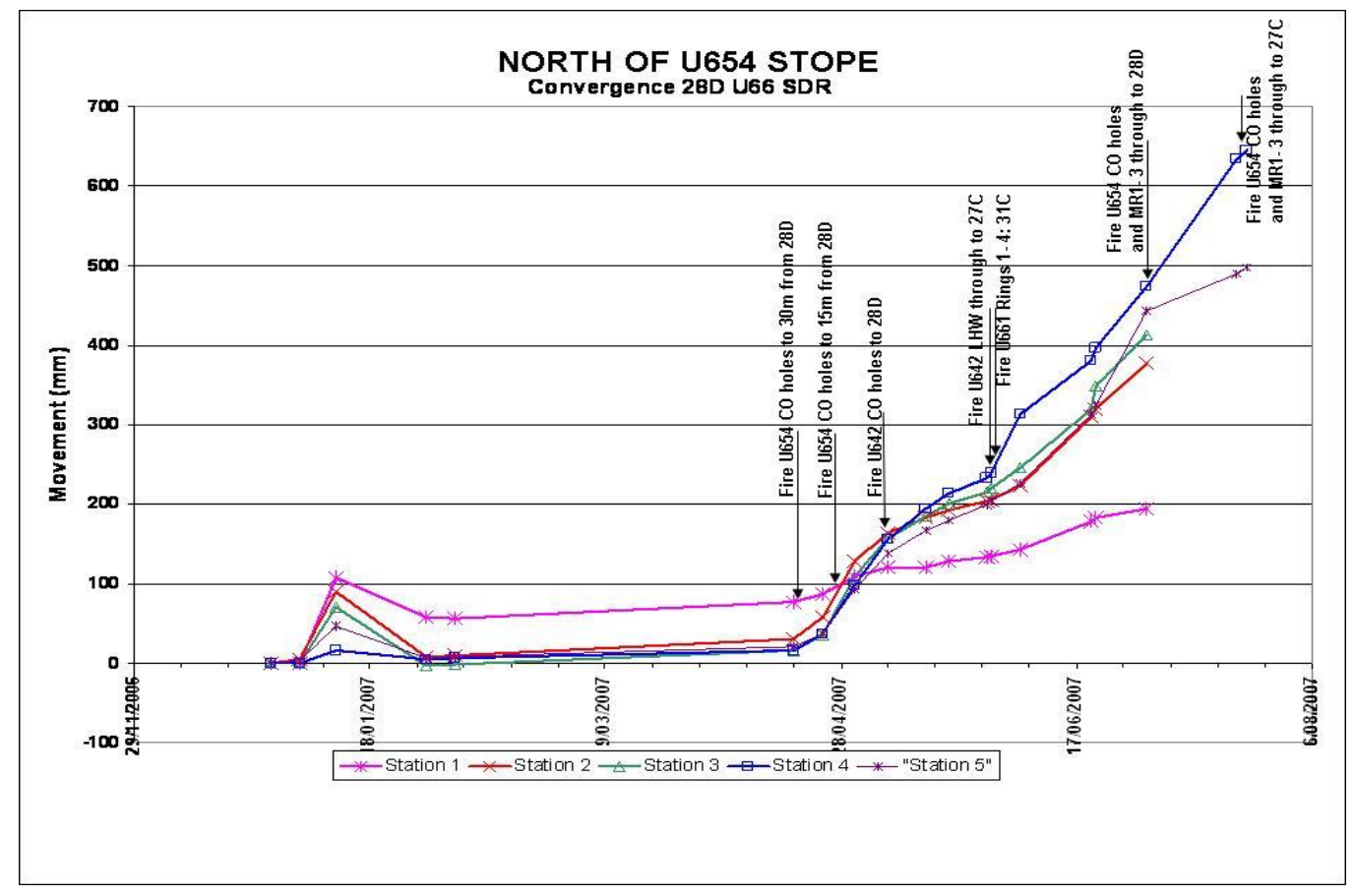

Figure 12 U654 drive deformation on 28D level

The stope experienced fall-off up dip (as rings of drilled ore fell-off as well as some fall-off from the $\mathrm{N}$ and $\mathrm{S}$ walls). After the final blasting of U654 through to $27 \mathrm{C}$ Level, the area was closely monitored. Very minor fall-off in the crown was recorded and some fall-off continued from the $\mathrm{N}$ and $\mathrm{S}$ walls. Some minor fall-off was also observed from the stope hangingwall. Eventually the span reached a level where the crown became unstable, and significant overbreak occurred rapidly in a vertical direction up $40 \mathrm{~m}$.

Lessons learnt from the U654 stope extraction:

- The North domain is distinctly different to the South domain. The rock mass is 'softer', more deformable and prone to larger failures.

- The area north of $6500 \mathrm{~N}$ latitude (North domain) is more suitable for smaller stopes.

- Drawpoint support designs have to be able to resist large stress changes and deformation. MICO has implemented more rigorous support measures in drawpoints including a mixture of concrete shuttering, shotcrete arches, cables, mesh and split-sets for a period of years. The specific mix depends on anticipated conditions for the stope designed. The support is designed to limit drawpoint production associated delays due to poor rock mass or support conditions. Figure 13 shows an example of a drawpoint with the increased support installed. This drawpoint recently completed production without any delays due to poor drawpoint conditions.

- Designs must not only focus on grade and orebody geometry, but also fit the conditions in regard to geological structures, rock mass strength and deformability. Figure 14 shows the re-designed stopes (North domain).

- Access drives in this area require substantial support. Support must limit initial deformation, allow for some yield and still provide safe access.

- Instrumentation must be implemented to monitor and better understand the rock mass behaviour and thus assist to optimise stope performance.

- Non-linear modelling is considered to better predict performance and analyse risks. The current design process includes the use of MAP3D and empirical design methods. 


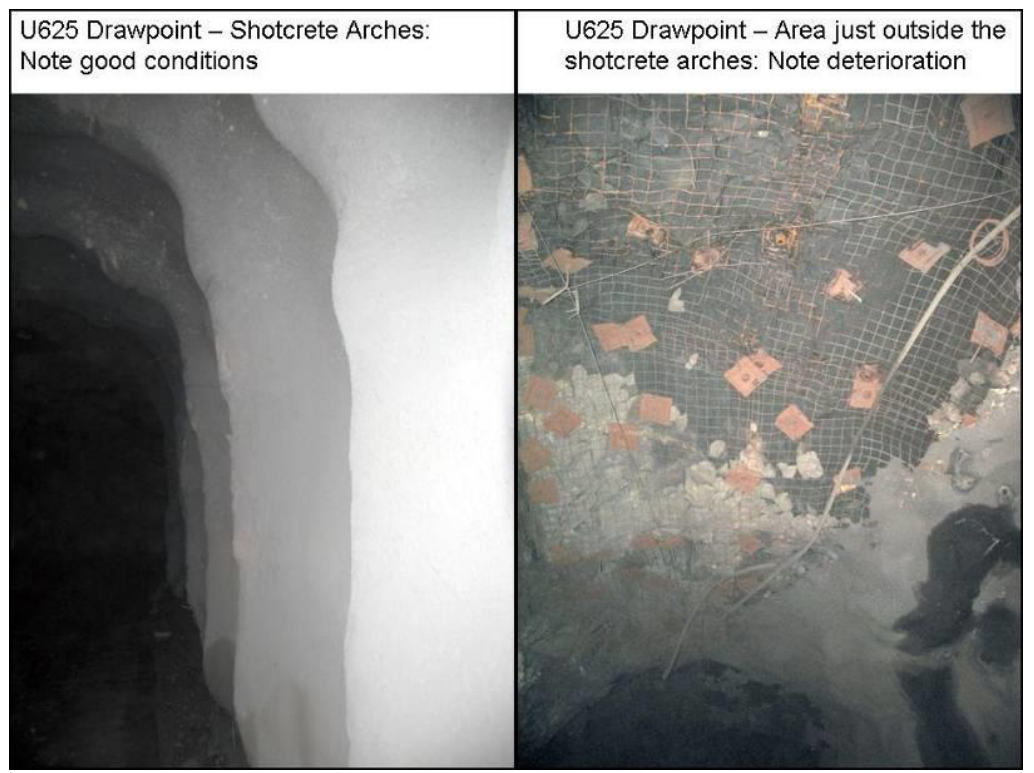

Figure 13 Photos comparing shotcrete arches versus conventional support

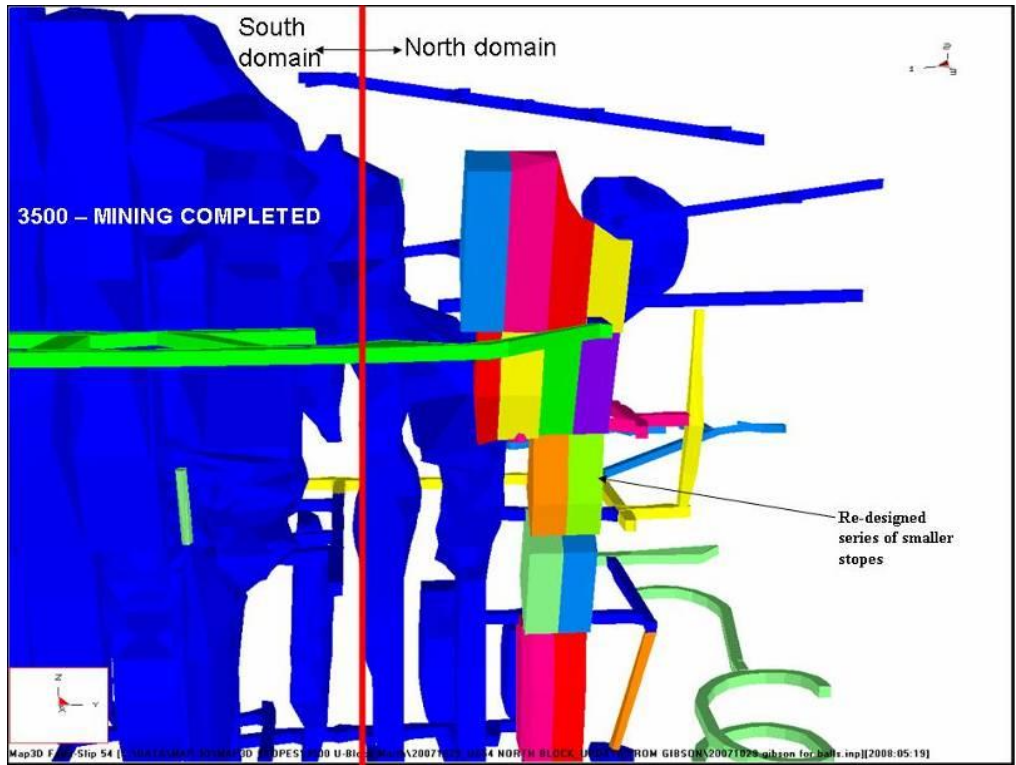

Figure 14 Re-designed stopes for the North domain of South $3500 \mathrm{OB}$

All of these concluding remarks are in place in the mining practices in MICO. Some were already in application in other areas of the mine prior to this event and this stope served as a catalyst to spread their application as well as confirm the need to mine small and stable stope in this 'softer' rock mass environment. MICO had already recognised the need to mine stopes of this smaller dimension (and some even smaller) in high copper grade ore further to the north, where the presence of talc mineralogy nearby can have a significant influence on safe and efficient extraction of ore.

\section{Recent support tests}

Cable bolt testing, above the standard and routine quality control work undertaken, has recently been conducted to investigate the effects of cable bolt 'bulbs' being squashed to a smaller diameter by the Tamrock Cabolter mechanised cable bolting machine. MICO has also undertaken work on product alternatives to be used in areas of the operations that experience higher than normal corrosion rates. Included 
are tests done on various types of mesh. This section contains some of the details on this work. Limited information on this has been included for the purpose of this paper.

\subsection{Cable bolt tests}

Some of the cable bolt tests have been done in conjunction with the University of New South Wales (UNSW). As described previously, the bulb issue was investigated after some observations made during installation underground. In addition other parameters such as hole diameter and grout setting times were also investigated and evaluated. These parameters were tested for straight cables, bulbed cables and 'squashed bulbed cables'. Squashed bulbs refer to bulbs squashed by the Tamrock Cabolter. Three sets of tests were done for each, including pipe tests with a discontinuity. $2.5 \mathrm{~m}$ and $300 \mathrm{~mm}$ pipe lengths were used. The results gave us a better understanding of how the cable bolts behave depending on type of cable, presence of discontinuities and length of encapsulation/embedment. Figures 15 and 16 show examples of tested bulbed cables.
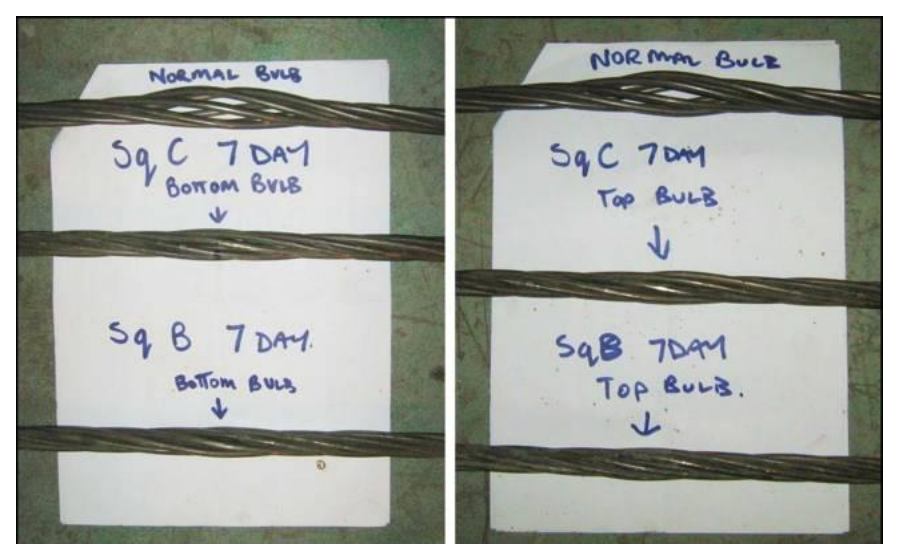

Figure 15 Squashed versus normal bulbed cables

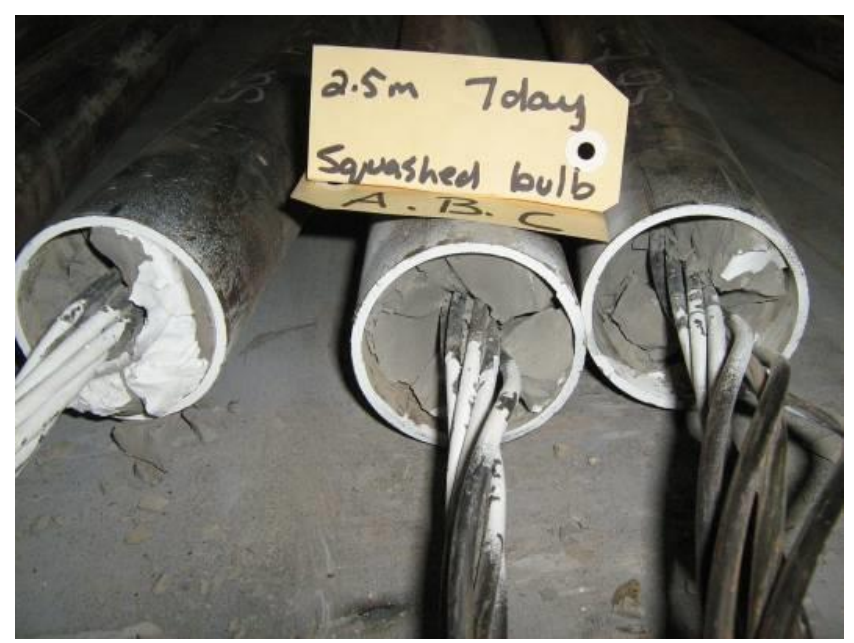

Figure 16 Pulled cables

Figure 17 illustrates the differences between a squashed bulb (19 mm diameter bulb) cable, a normal bulbed cable ( $25 \mathrm{~mm}$ diameter Garford bulbs, and a straight cable (no bulbs). This is after seven days grout setting time. Note that straight cables without bulbs have a longer potential application life in deforming ground as it allows for more movement/displacement prior to yielding. The normal bulbed cable is 'stiffer' and reaches higher loads with less displacement. The cable with the squashed bulbs performed less 'stiffly', but with less yield (the peak loads are the same - however the displacements required to produce those loads is the difference) compared to the straight cable. 


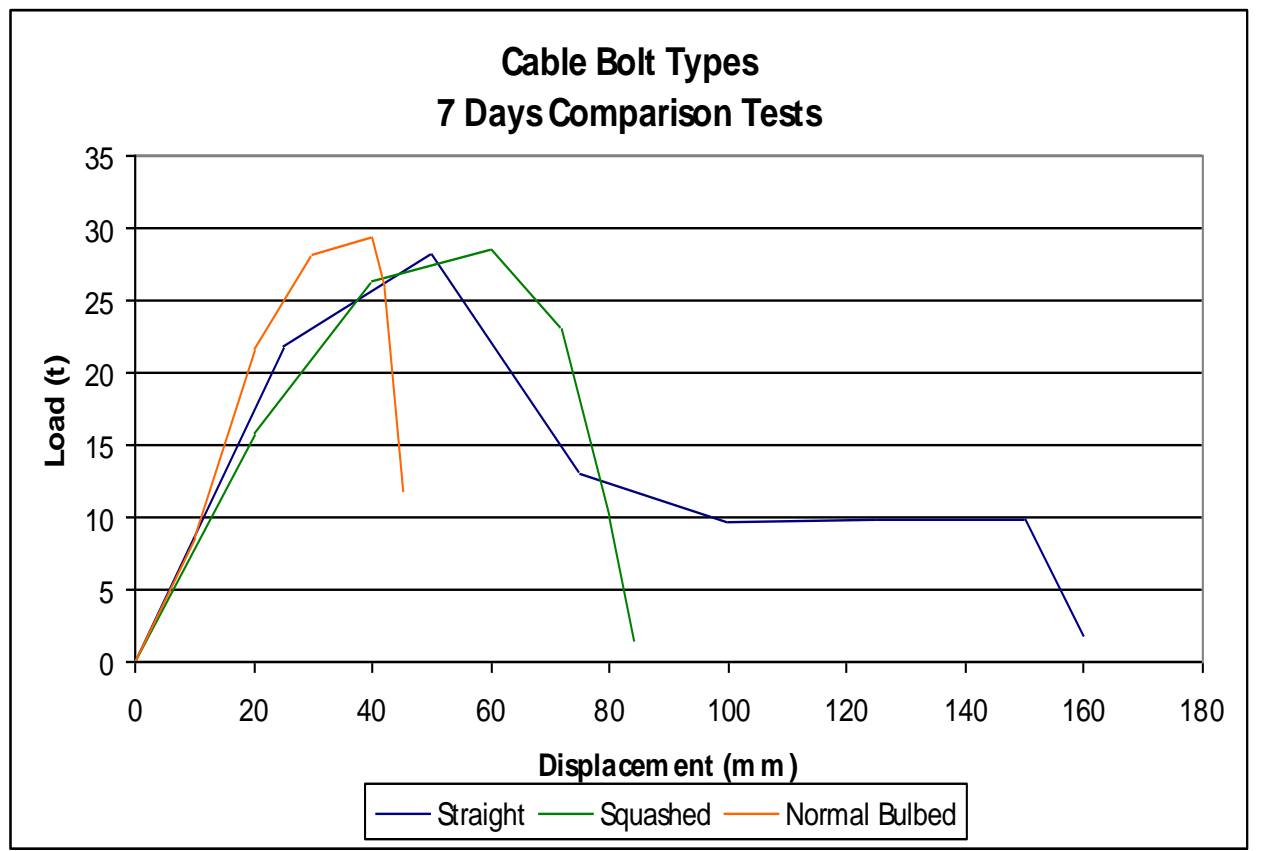

Figure 17 Seven day grout setting time. Note the higher strength at low displacement for normal bulbed cable versus similar strengths but more displacement required for the others

Figure 18 illustrates results from similar tests, this time for an eight hour setting time. In this case the normal bulbed cable outperforms the others in terms of both ultimate strength and yield.

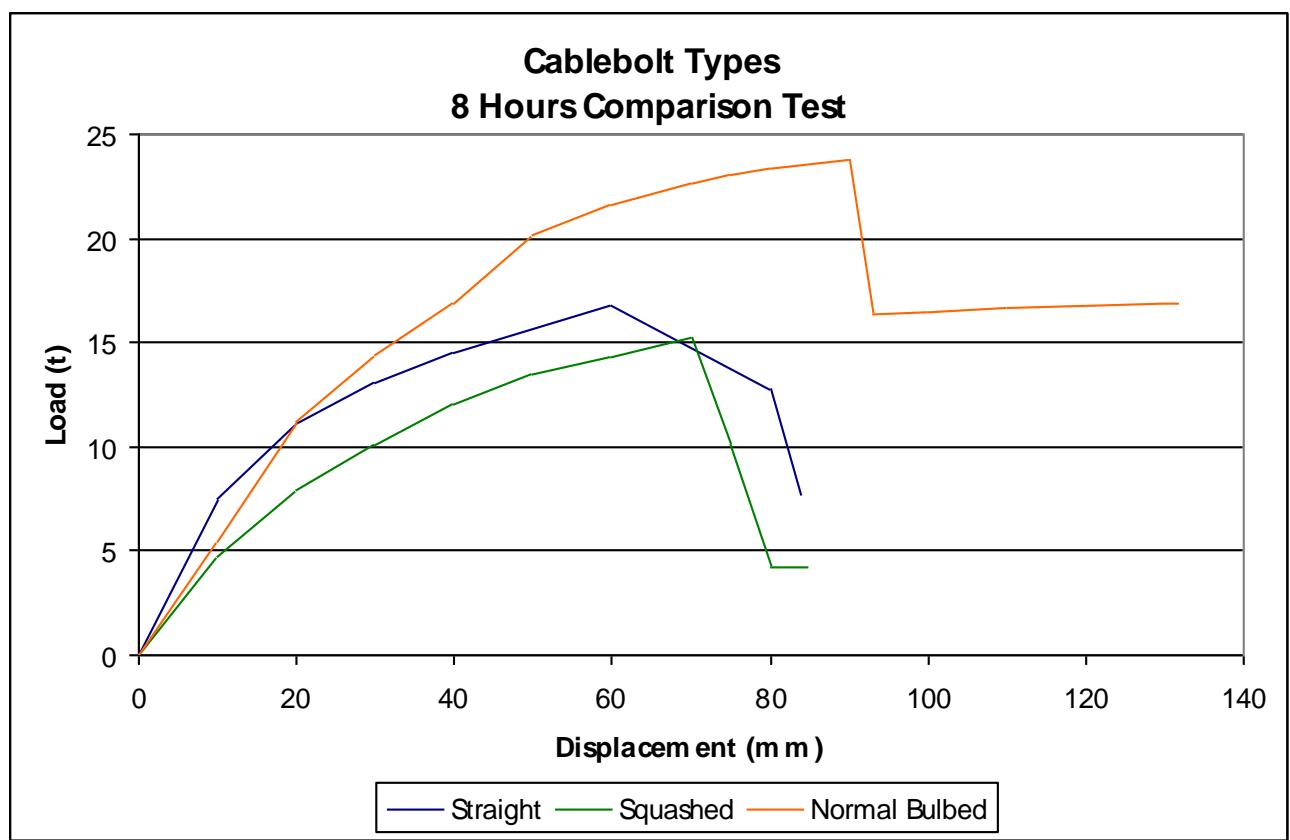

Figure 18 Note that after eight hours a normal Garford bulbed cable (not squashed or straight) outperforms the other two options 


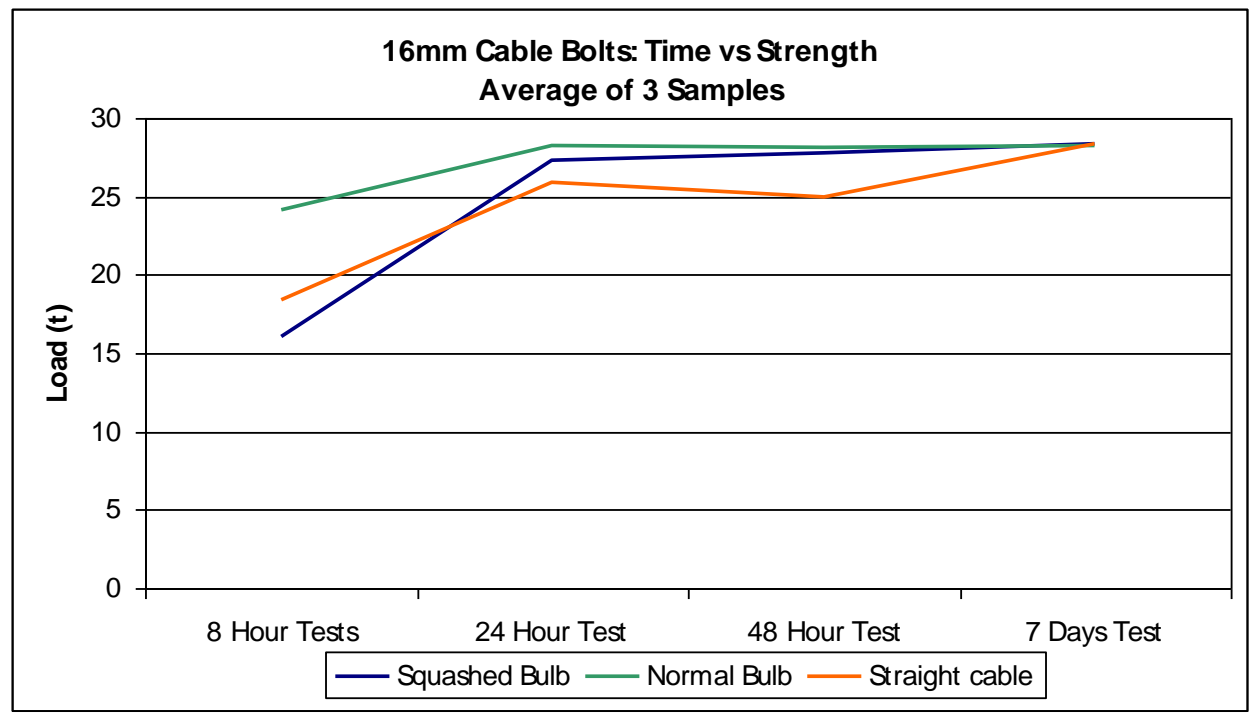

Figure 19 Note the higher earlier strength achieved with a 'normal' bulbed cable

MICO collaborated with the UNSW on project work done by S. Mosse-Robinson as part of an undergraduate thesis. Part of this work investigated the effect on cable bolt performance of different bulbs per metre options, water cement (w:c) ratios, curing time and hole diameters. From this work it became apparent that hole diameter does not have a large effect on ultimate loads achieved, provided that there has been adequate curing time for the grout. The larger pipe diameters do however, allow for more slip to occur. Where early and higher strength are required, it is recommended to use smaller hole diameters, proper bulbed cable and more bulbs per metre. Where yield is required, straight cables without bulbs will result in more yield and thus a longer life in an ongoing deforming environment. Figures 20 and 21 illustrate some of the results from this work.

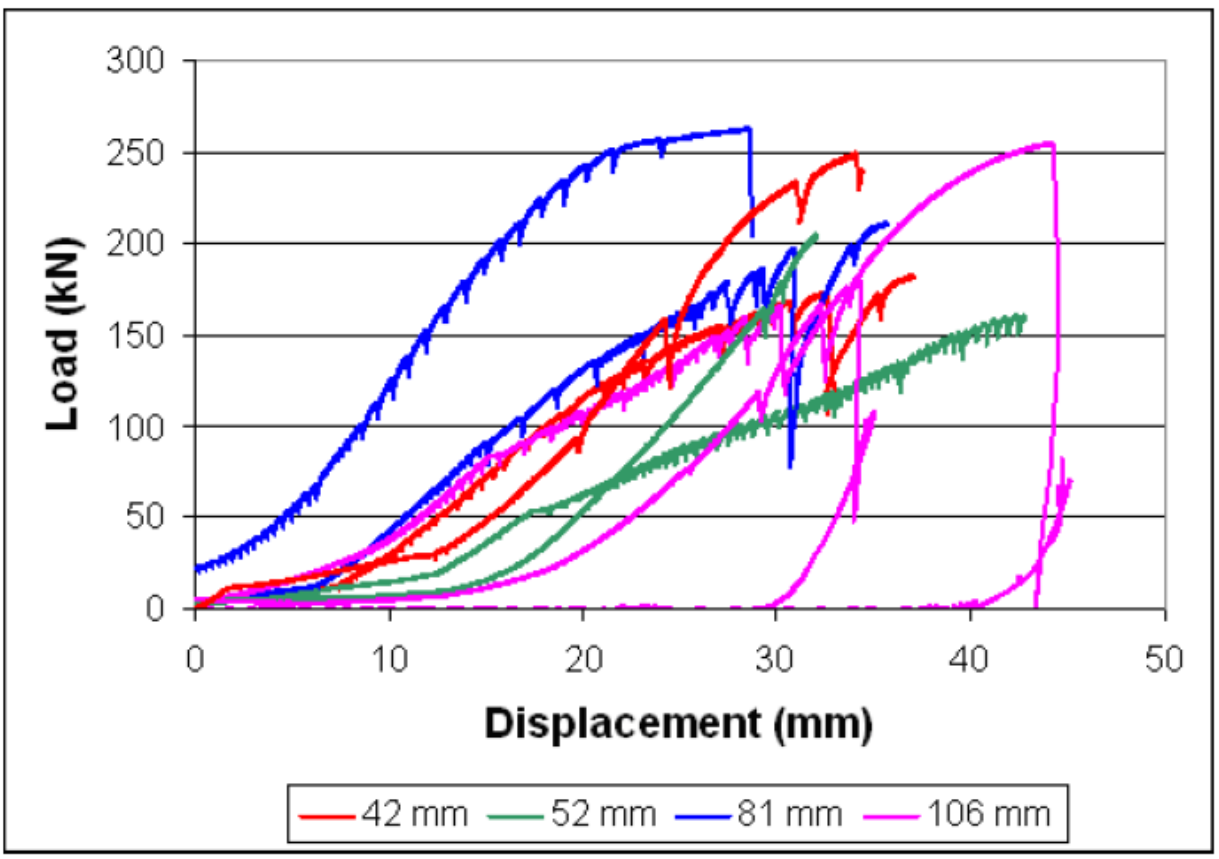

Figure 20 Larger pipe diameter $(106 \mathrm{~mm})$ result in more yield before ultimate strength is achieved 14 days curing time (after S. Mosse-Robinson, 2007) 


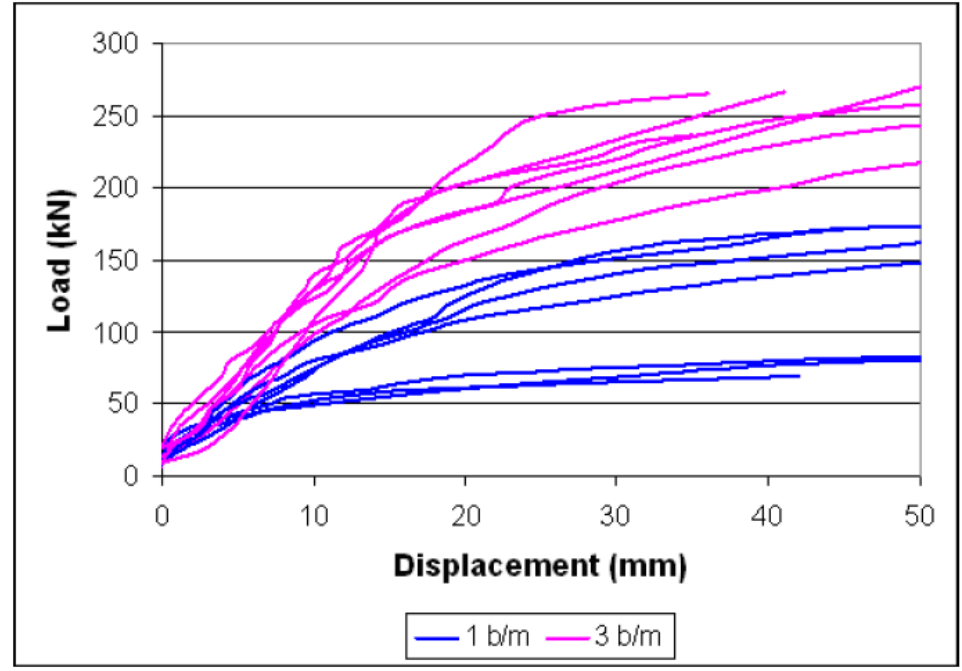

Figure 21 Note the higher loads achieved by using three bulbs per metre at early age of curing (one day) (after S. Mosse-Robinson, 2007)

\subsection{Mesh tests}

The mesh tests described below are part of a project initiated at MICO to further investigate and better understand the effect, causes and influencing factors of ground support corrosion. Other work on this project include routine water sampling and analysis, investigating and testing of ground support alternatives, monitoring underground factors that influence corrosion, and work on a ground support corrosion strategy. This strategy will outline support types to be used for different corrosive conditions and actions to be followed where future excavations are expected to be affected by corrosion.

Corrosion of ground support can be costly from both a safety and economic point of view. A common contributing factor to rockfall events is corrosion at MICO and the MICO operation ensures a strong focus on rehabilitation works in the operations to mitigate this risk. Where support is badly corroded, rehabilitation is required which results in drilling resources being taken away from new development drive mining. This ultimately leads to constraints on the mine planning schedule and a need for more resources. At MICO corrosion can sometimes be rapid (six months), and in some instances the same working place has been rehabilitated three or four times over the life of the excavation. Better ground support products and better control over conditions can have a significant influence on the overall productivity of the mine. Depending on the conditions, shotcreting can be used as an alternative, in some instances in combination with mesh.

Mount Isa Mines currently use two types of mesh: black steel mesh and galvanised mesh. The use of galvanised mesh can at times not be effective due to high water temperatures, continuous water presence, water quality issues and preferential corrosion issues (zinc is more anodic compared to black steel). (Internal report: D. Tyler, 1999; and Report \#263, Meriwa Project 333; Villaescusa et al., 2007). Other mesh types were investigated as possible alternatives, especially where rehabilitation must be done in wet areas, where galvanised products will be ineffective and where shotcrete is not effective or available.

Several types of polymer mesh varieties were tested as alternatives to steel mesh to overcome corrosion. The results were compared to tests done on steel weld mesh. In order to test the mesh an instrumented testing rig was designed and built. Figure 22 shows the mesh testing rig. The rig measured load, vertical displacement and cross-sectional stretch of the mesh.

These mesh tests were conducted on a $1.2 \times 1.2 \mathrm{~m}$ bolt spacing. The platen used to stretch the mesh has an uneven surface of underground rocks that were attached to the platen to simulate the potential cutting of the mesh by sharp rocks. Up to $250 \mathrm{~mm}$ of cross-sectional elongation of the mesh was recorded for both the steel and polymer mesh. 


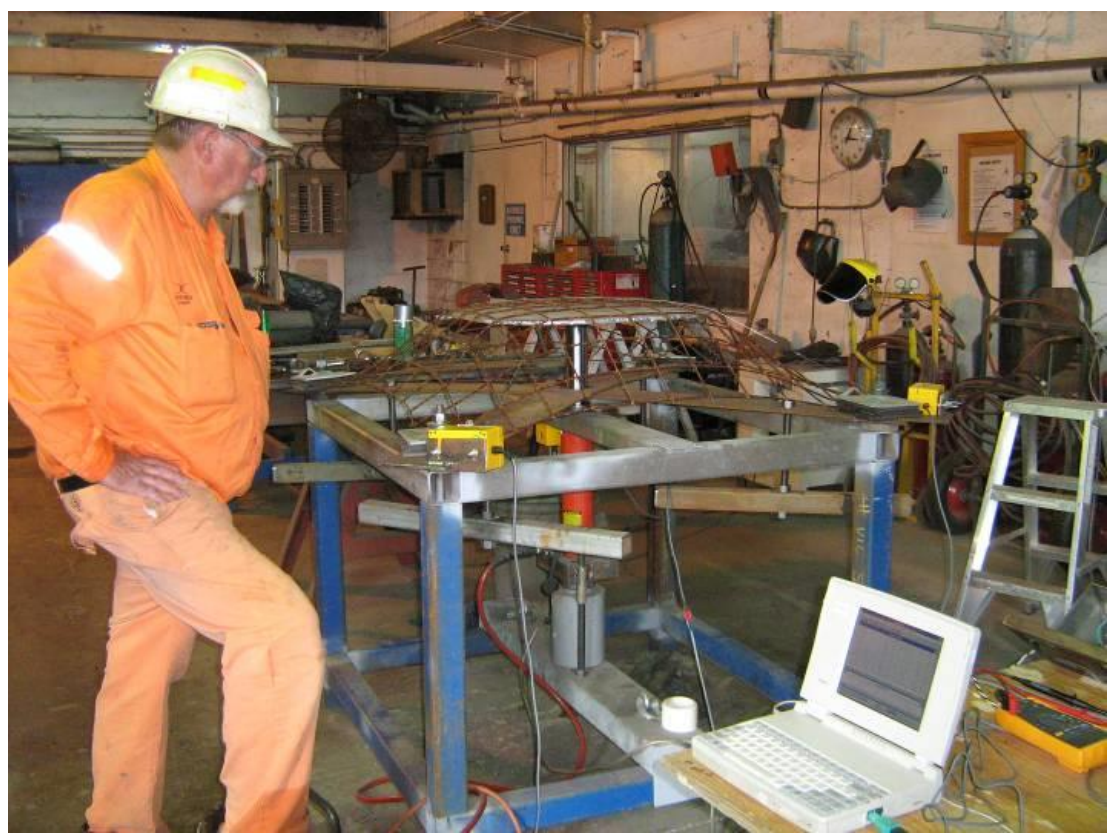

Figure 22 Mesh testing rig built by MICO staff, including V. Stampton

The base tests involved testing steel mesh until failure occurs. Failure was noted to occur on the welded intersection of strands. Failure occurred between 1.8 and 2.1 t. Figures 23 and 24 show the results of black steel mesh compared to a polymer type mesh (called HAS). Note that some of the steel mesh samples also achieved $2 \mathrm{t}$. This was the only polymer or geogrid type mesh that could relatively closely match black steel in the results. All other geogrids tested were found to have inadequate strength or baggage capacity. The advantage of the polymer mesh is that it does not corrode and therefore has a longer life than steel. It is also not as expensive as stainless steel alternative products. MICO will now start to investigate the opportunities and challenges with underground development mining trials of this polymer mesh where operational practical application will be of importance.

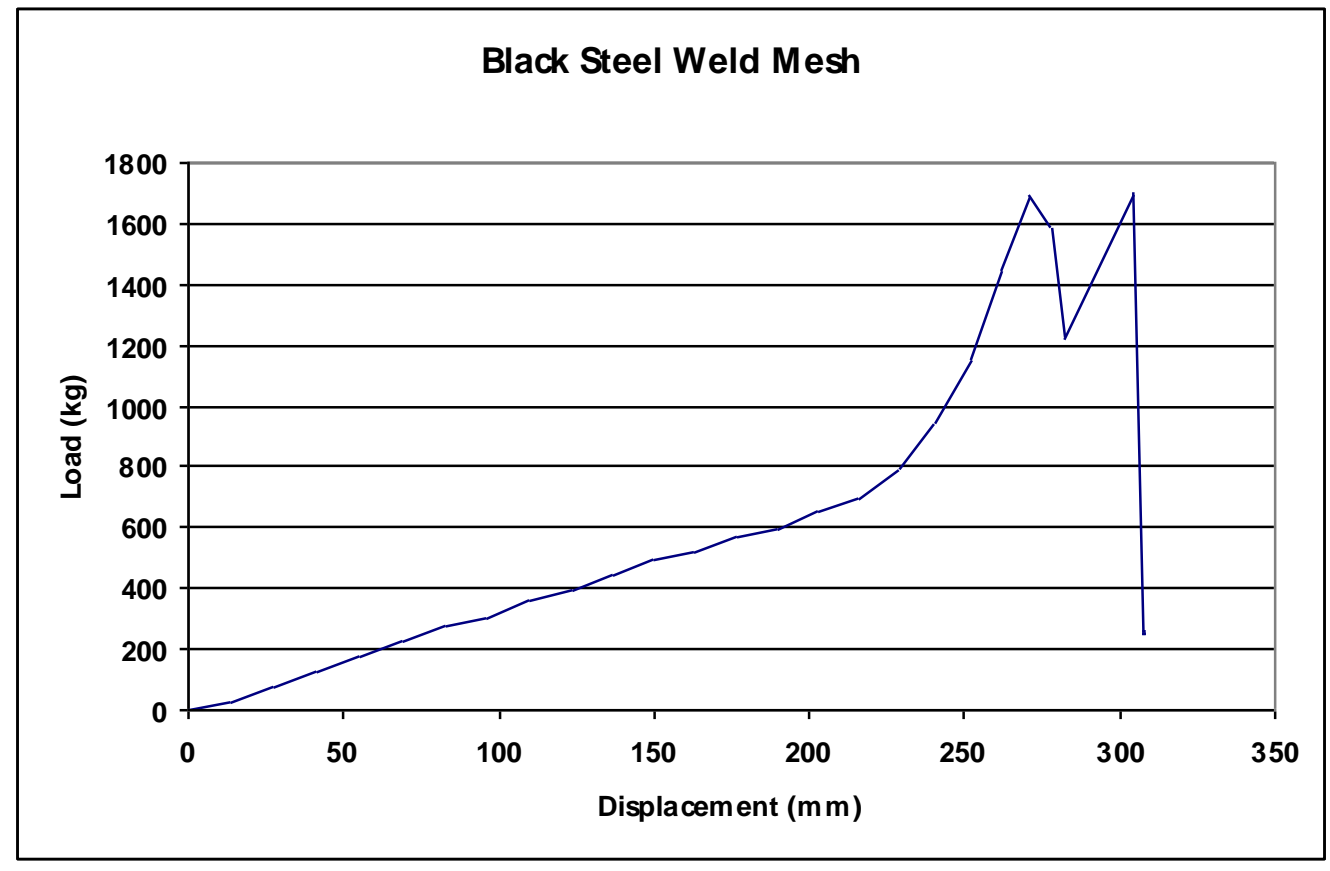

Figure 23 Note ultimate strength of steel mesh: $1.7 \mathrm{t}$ 


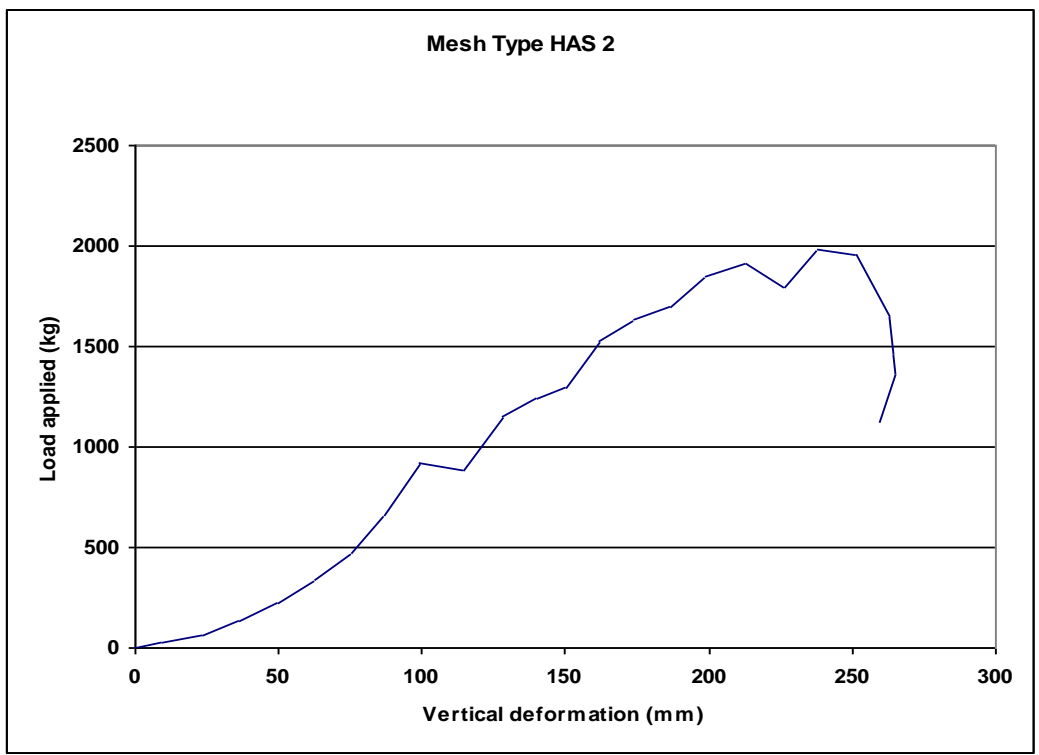

Figure 24 Note ultimate strength of HAS polymer mesh: $2 \mathrm{t}$

Figure 25 graphically illustrates the amount of stretch the steel mesh can accommodate before failure. Figure 26 illustrates the HAS mesh being loaded to failure. The steel mesh failed on the welding, whilst the HAS polymer mesh failed through tearing individual strands apart around the tendons.

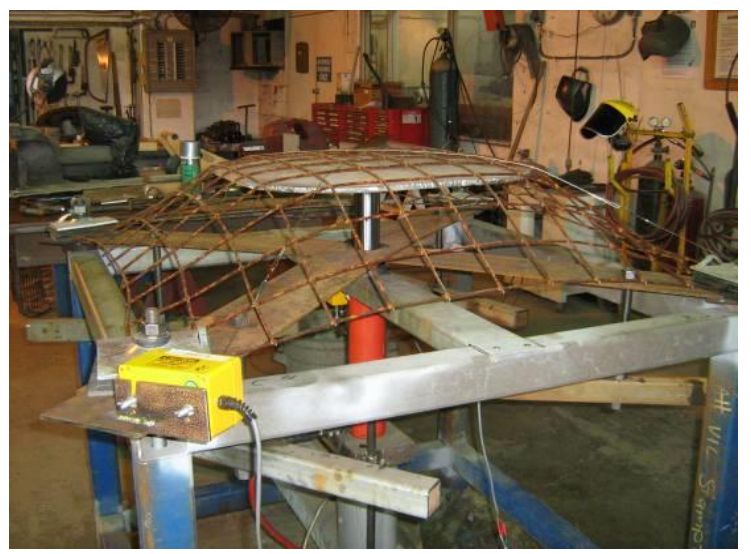

Figure 25 Black steel mesh test

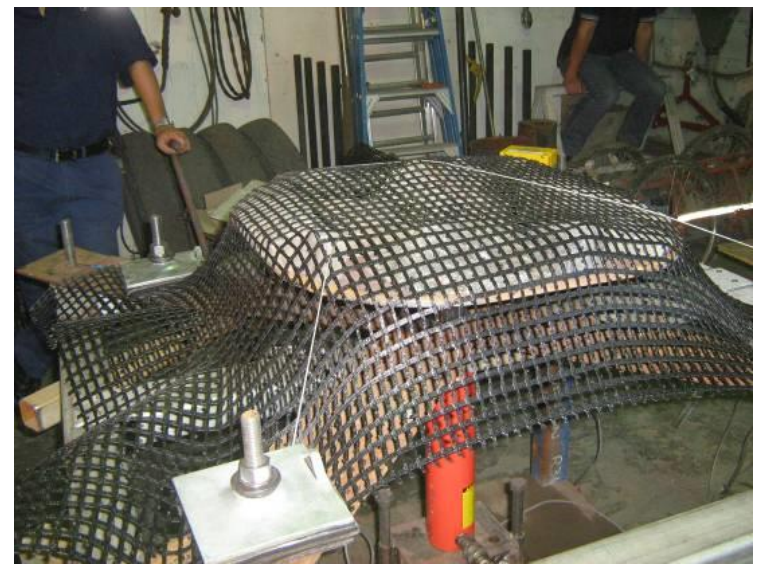

Figure 26 HAS polymer mesh test 


\section{Conclusions}

Stope blocks need careful consideration of the local conditions present. Designs should be done to fit geotechnical conditions.

The 3500 orebody has two distinct domains, the North domain and the South domain. Designs and production should take the differences between the domains into consideration.

The re-designed North domain will be monitored and further analysed to optimise the performance and quantify the effect of the changes.

Alternative support types are needed to reduce the effect of corrosion on ground control. A strategy to better control the effect of corrosion is under development.

The potential squashing of cable bolt bulbs by mechanised installation needs to be checked and where needed, fixed. Squashed cable bolts will reduce the early strength required in some underground applications. Cables should suit the rock mass conditions and purpose. Use smooth or specialist yielding cables where required.

\section{References}

Foster, D.R.W., Rubenach, M.J. and Oliver, N.H.S. (2007) Distribution, Formation, and effective measurement of Talc in the N3500 Mount Isa Orebody.

Mosse-Robinson, S. (2007) Laboratory experiments to quantify the pull out strength of cable bolts, Thesis, The University of New South Wales, 2007.

Tarrant, G. and Lee, M. (1984) Mount Isa Rock Properties.

Tyler, D. (1999) Cause and rates of corrosion in ground reinforcement elements - Mount Isa and Hilton mine leases.

Villaescusa, E., Hassel, R. and Thompson, A. (2007) Corrosion of Rock Reinforcement in Underground Excavations, MERIWA Report No. 263, Project No. M333. 